\title{
Home ranges of cheetahs (Acinonyx jubatus) outside protected areas in South Africa
}

\author{
Kelly Marnewick ${ }^{1,2^{*}}$ \& Michael J. Somers ${ }^{1,3}$ \\ ${ }^{1}$ Centre for Wildlife Management, University of Pretoria, Pretoria, 0002 South Africa \\ ${ }^{2}$ Carnivore Conservation Programme, Endangered Wildlife Trust, Private Bag X11, Modderfontein, 1645 South Africa \\ ${ }^{3}$ Centre for Invasion Biology, University of Pretoria, Pretoria, 0002 South Africa \\ Received 29 September 2014. To authors for revision 28 October 2014. Accepted 17 June 2015
}

\begin{abstract}
As many carnivores occur outside protected areas, they are vulnerable to anthropogenic threats. In South Africa, the largest proportion of the distribution range of cheetahs (Acinonyx jubatus) is outside protected areas along the northern border of the country. Lions (Panthera leo) and spotted hyaenas (Crocuta crocuta) have been extirpated from these areas, leaving the depauperate carnivore guild dominated by cheetahs, leopards (Panthera pardus) and brown hyaenas (Hyaena brunnea). To determine how cheetahs use these areas, tracking collars were fitted to nine individuals from September 2003 to July 2009 in the Thabazimbi area, Limpopo, South Africa. Local Convex Hulls $(\alpha \mathrm{LoCoH})$ were used to determine home range sizes and 50 and 95 utilization distributions (UDs) were calculated. Male 95UDs ranged from $121.5 \mathrm{~km}^{2}$ to $607 \mathrm{~km}^{2}$ while females ranged from $14.7 \mathrm{~km}^{2}$ to $703.3 \mathrm{~km}^{2}$. Cheetahs utilized several ranches and mean home ranges sizes were larger than mean ranch size and larger than cheetah home ranges recorded in other southern African countries, with the exception of the more arid Namibia. This study provides valuable and relevant data on cheetahs and aids conservation practitioners in mitigating human-cheetah conflict on South African farmland.
\end{abstract}

Key words: African carnivores, Local Convex Hulls, conservation threats.

\section{INTRODUCTION}

A key function of protected areas is to separate biodiversity elements from processes that threaten them (Margules \& Pressey, 2000). The designation of protected areas has seldom been done in a systematic way and as a result, protected areas are not always effective in contributing to biodiversity conservation (Margules \& Pressey, 2000). This means that many species which occur outside protected areas in regions of anthropogenic use are vulnerable to the effects of habitat fragmentation (Ranta, Blom, Niemela, Joensuu \& Siitonen, 2009) and conflict-related killings (Swanepoel, Lindsey, Somers, van Hoven \& Dalerum, 2014) and other threats.

Large carnivores are particularly vulnerable to threats in fragmented landscapes as they have high space requirements, live at low densities and inevitably come into conflict with humans (Purvis, Gittleman, Cowlishaw \& Mace, 2000; Cardillo et al., 2005). While protected areas are important for carnivore conservation, they are seldom effective

*Author for correspondence.

E-mail: kellym@ewt.org.za / kellymarnewick@gmail.com in their conservation (Woodroffe \& Ginsburg, 1998). Conservation of carnivores therefore cannot rely solely on protected areas, and needs to be addressed both within and beyond the boundaries of these areas.

In South Africa, the protected area network alone is not sufficient for conserving populations of large carnivores. For example, leopards (Panthera pardus) are vulnerable to edge effects (Balme, Slotow \& Hunter, 2010), habitat fragmentation and ineffective positioning of protected areas (Swanepoel, Lindsey, Somers, van Hoven \& Dalerum, 2013); and only two protected populations of lions (Panthera leo) (Kruger National Park and Kgalagadi Transfrontier Park) are classified as viable (IUCN/SSC, 2006), with lions in smaller protected areas being vulnerable to genetic, ecological and stochastic effects (Miller et al., 2013). Ecological niche modelling shows that the protected area network is also not effective in conserving the most suitable habitat for cheetahs (Acinonyx jubatus) and African wild dogs (Lycaon pictus) in South Africa (K.M., unpubl. data).

The Kruger National Park and the Kgalagadi 
Transfrontier Park hold the only substantial populations of cheetahs inside protected areas in South Africa (Lindsey \& Davies-Mostert, 2009), with the largest portion of the national cheetah distribution range occurring outside protected areas along the northern border of the country (Marnewick et al., 2007). Lions and spotted hyaenas (Crocuta crocuta) have been extirpated from these areas, leaving the depauperate carnivore guild dominated by cheetahs, leopards and brown hyaenas (Hyaena brunnea). In these areas, land is privately owned and utilized for wildlife ranching, livestock ranching or a combination thereof. Both livestock and wildlife have an economic value to the landowner; livestock through live sale or the meat industry and wildlife through sport hunting and live sale. Thus when carnivores prey on these animals, conflict results and the suspected carnivore is often killed in retaliation or in an effort to prevent further losses (Thorn, Green, Marnewick \& Scott, 2013). Cheetahs are classified as Vulnerable in the South African Red Data Book of Mammals (Friedmann \& Daly, 2004) and the South African population is contiguous with the populations in Botswana, Namibia, Zimbabwe and Mozambique (IUCN/SSC, 2007). These factors make the cheetah population outside protected areas important for conservation of the species.

Few data exist on cheetahs outside protected areas in South Africa. Some landowners perceive cheetahs to be problematic as they claim cheetahs do not behave naturally in these areas. Ranches are heavily stocked with game and supported by supplying food and water. Because the ranches are fenced and the prey is sedentary, many landowners believe that cheetahs do not use large home ranges as is typical in other areas. This means that the impact of cheetahs on any individual ranch is perceived to be high (K.M., unpubl. data).

These perceptions are important in driving killing of cheetahs and thus their long-term survival outside protected areas. Data relevant to the landowners are required to address these perceptions and to implement cheetah conservation actions. This study therefore attempts to quantify the home ranges of cheetahs outside protected areas on private ranches.

\section{METHODS}

\section{Study area}

The Thabazimbi District in the Limpopo province was the core study area. The area was selected because previous surveys had been done in the district and a relationship had been developed with the landowners (Marnewick \& Cilliers, 2006; Marnewick, Bothma \& Verdoorn, 2006; Wilson, 2006). Thus, landowner buy-in had been obtained for the study with the resulting permissions to trap, collar and release cheetahs on several properties. The mean ranch size in the district is approximately $18 \mathrm{~km}^{2}$ with the main form of land-use being wildlife ranching, or a combination of wildlife and livestock ranching (Wilson, 2006). The area is topographically flat with little change in elevation and few distinguishing geographic features.

The Thabazimbi District lies in the Savanna Biome of South Africa and the main vegetation type is Mixed Bushveld dominated by the red bushwillow (Combretum apiculatum), common hook-thorn (Acacia caffra), sickle bush (Dichrostachys cinerea), live-long (Lannea discolour) and marula (Sclerocarya birrea) (Low \& Rebelo, 1996). Where the soil is more clayey, Clay Thorn Bushveld occurs which is dominated by Acacia species (Low \& Rebelo, 1996). The area has been historically used for cattle (Bos taurus) ranching and the bush is encroached over a large portion of the district (K.M., pers. obs). There are some previously ploughed areas that have since been left fallow. The edges between these areas and the surrounding more dense, bushy areas are generally hard and linear.

The annual, mainly summer, rainfall for the study area varies from $350 \mathrm{~mm}$ to $650 \mathrm{~mm}$ per year with temperatures ranging from $-8^{\circ} \mathrm{C}$ to $40^{\circ} \mathrm{C}$ with an annual mean of $21^{\circ} \mathrm{C}$ (Low \& Rebelo, 1996). Human population density is low at $2 / \mathrm{km}^{2}$ (Statistics South Africa (2001) www.statssa.gov.za accessed on FUNDISA Disk).

\section{Cheetah capture}

Cheetahs were trapped from September 2003 to July 2009 using double-door box traps along frequently walked fence lines, at scent marking posts and using live bait. For more detailed information on trapping procedure see Marnewick \& Cilliers (2006). Trapped cheetahs were immobilized by a wildlife veterinarian and fitted with tracking collars. All activities involving cheetah handling and research were done under a University of Pretoria Animal Ethics Committee permit (No. EC030-09) and permits issued by the Limpopo Department of Economic Development, Environment and Tourism (the local government conservation authority). 
If coalitions were caught then only one member of the group was collared as this group structure is normally stable and these males can be expected to remain together (Caro, 1994). Initially VHF collars (African Wildlife Tracking, Pretoria, South Africa) were fitted and the cheetahs monitored by microlight aircraft. Once the technology was available and affordable, GPS/GSM collars (African Wildlife Tracking, Pretoria, South Africa, and Hot Group, Pretoria, South Africa) were used to obtain more robust data and set to take two to four GPS locations per day; 12:00 and 00:00 for the collars set for two daily locations, and with 06:00 and 18:00 included for the collars with four daily locations. The cheetahs were allowed to recover from immobilization in the trap cage and once fully recovered, were released at the site of capture. Cheetahs were monitored for the extent of their life or the life of the collar. On two occasions, the collars were replaced due to deteriorating batteries by darting the cheetahs from a helicopter. Three female and six male cheetahs were collared. Four of the males were singletons, one from a collation of three and one from a coalition of two, resulting in nine monitoring units (Fig. 1). None of the females had cubs or showed any signs of lactation.

Trapping success was low with approximately 278 trap days required to trap a cheetah, or monitoring unit. Cheetahs were monitored from 28 days to 2119 days depending on the life of the cheetah or the collar (see Table 1). The two male (AM196) and three male (AS68) coalitions were initially monitored using VHF collars resulting in $56(2.8 \%$ of total) and 12 (8.6\% of total) data points being obtained, respectively.

\section{Data analysis}

Local Convex Hulls ( $\alpha$ LoCoH) (Getz \& Wilmers, 2004; Getz, Fortmann-Roe, Lyons, Ryan \& Cross, 2007) were used to determine home range sizes, using the computer programme $\mathrm{R} v 2.10 .1$ (The $\mathrm{R}$ Foundation http://www.R-project.org/). Utilization distributions (the two-dimensional distribution of the position of an animal (Worton, 1989) were considered at two spatial scales where 50 utilization distributions represented core areas and 95 utilization distributions represented total ranges. $\mathrm{K}$, the number of nearest neighbour points used to construct local hulls to obtain a utilization distribution, was calculated using the square root of the total number of data points per animal (Getz et al., 2007).

LoCoHs have been shown to outperform kernels and provide a more accurate representation of the animals' home range, especially in areas with hard boundaries (Getz et al., 2007). Minimum Convex Polygons (MCP) (Jenrich \& Turner, 1969) (Hawth's Analysis Tools ARC GIS V 3.27 2006; www.spatialecology.com/htools) were determined and used to allow for comparison with other studies, because the method is widely used (Harris et al., 1990). For area calculations, the data were projected into UTM. Home range size using MCPs was plotted against sequential GPS locations in the software package Abode Beta V2 (Laver, 2005; http://fishwild.vt.edu/abode/ abodeweb.html) to visually determine if home ranges reached asymptotes. Relationships between male and female home range sizes, maximum distances moved and proportion between total and core ranges were tested using appropriate statistical tests.

\section{RESULTS}

\section{Fate of the collared cheetahs}

Two of the females were shot by landowners and one was killed in a road accident. The coalition of three males was shot as was one of the single males, the coalition of two died from what appeared to be natural causes, three single males have unknown fates as the collar downloads stopped. They either died and the collars were destroyed, were out of cell phone reception, or the collars malfunctioned. Five of the nine collared cheetahs died due to anthropogenic causes.

\section{Home range sizes}

The home range sizes of all females reached an asymptote. Male home ranges appeared to be larger than female ranges but they did not all reach asymptotes (Fig. 2) and these differences were not significant for the MCP $\left(t_{(7)}=-0.8, P=0.22\right)$, 95UD $\left(t_{(7)}=-0.7, P=0.46\right)$ or 50UD $\left(t_{(7)}=0.77\right.$, $P=0.23$ ). Male 95UDs ranged from $121.5 \mathrm{~km}^{2}$ to $607 \mathrm{~km}^{2}$ while females ranged from $14.7 \mathrm{~km}^{2}$ to $703.3 \mathrm{~km}^{2}$ (Fig. 3a). The 50UD (Fig. 3b) as a percentage of the 95UD was $18 \%$ for females, $10 \%$ for males and $12 \%$ across all sexes. There was no significant difference between the maximum distances between points for males and females $\left(t_{(7)}=-1.14, P=0.15\right)$.

\section{DISCUSSION}

Owing to the low trapping success of 278 trap nights per cheetah, our sample size was low. The data collected did not allow for analysis of sea- 


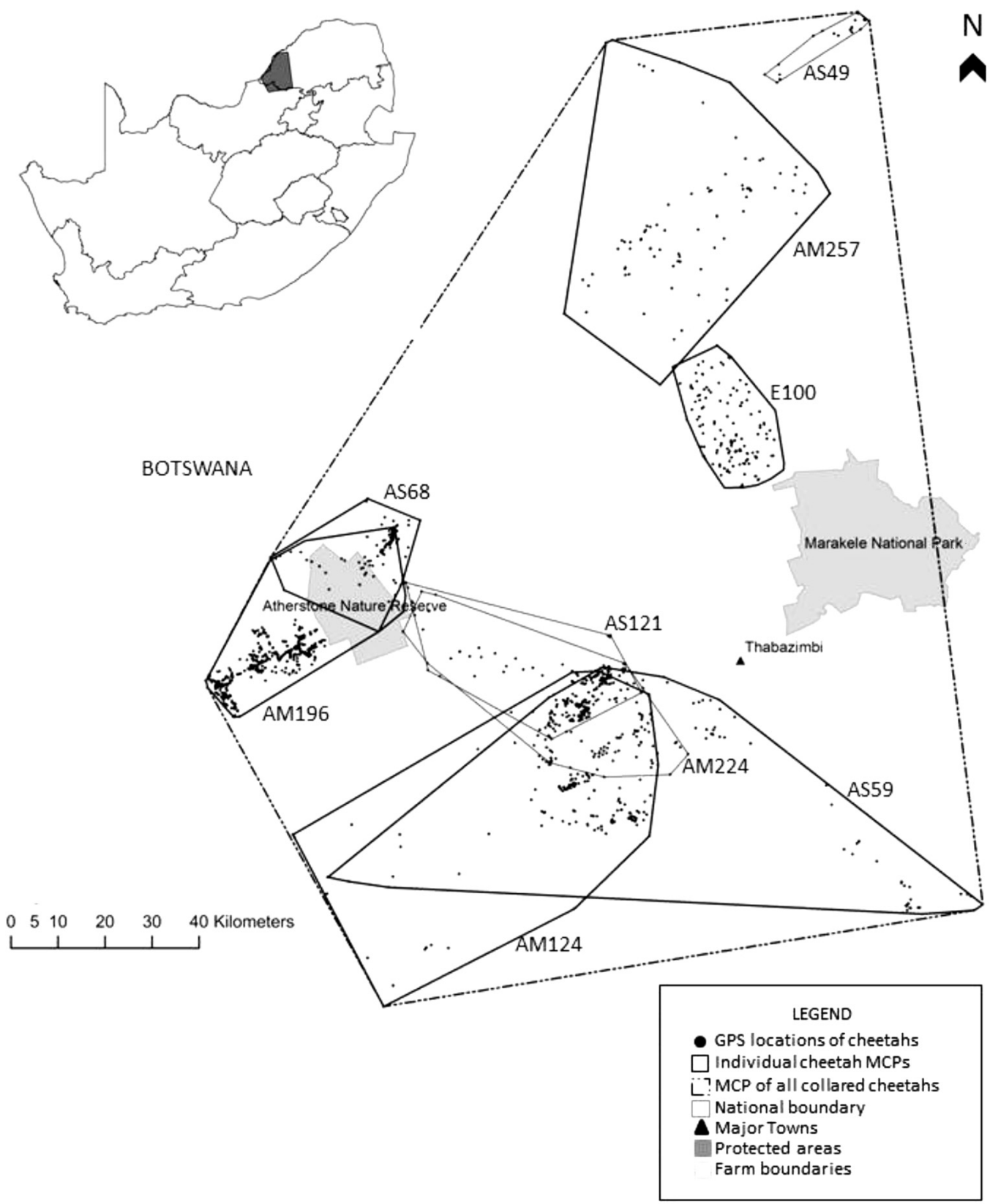

Fig. 1. The study area in Limpopo province, South Africa, where free-roaming cheetahs were collared. MCPs for each cheetah are shown along with protected areas, farm boundaries and major towns.

sonal range use as only the coalition of two males were monitored for longer than one year. However, this study is still valuable in assessing cheetah movement in a ranching area and provides new information to assist conservation practitioners in conflict mitigation and conservation researchers on the effort required to derive robust home range estimates for cheetahs (c. 343 locations).

Cheetahs in Thabazimbi have large home ranges similar to cheetahs outside protected areas in other southern Africa countries. All studies on cheetahs outside protected areas show larger home ranges than cheetahs in the Kruger National 


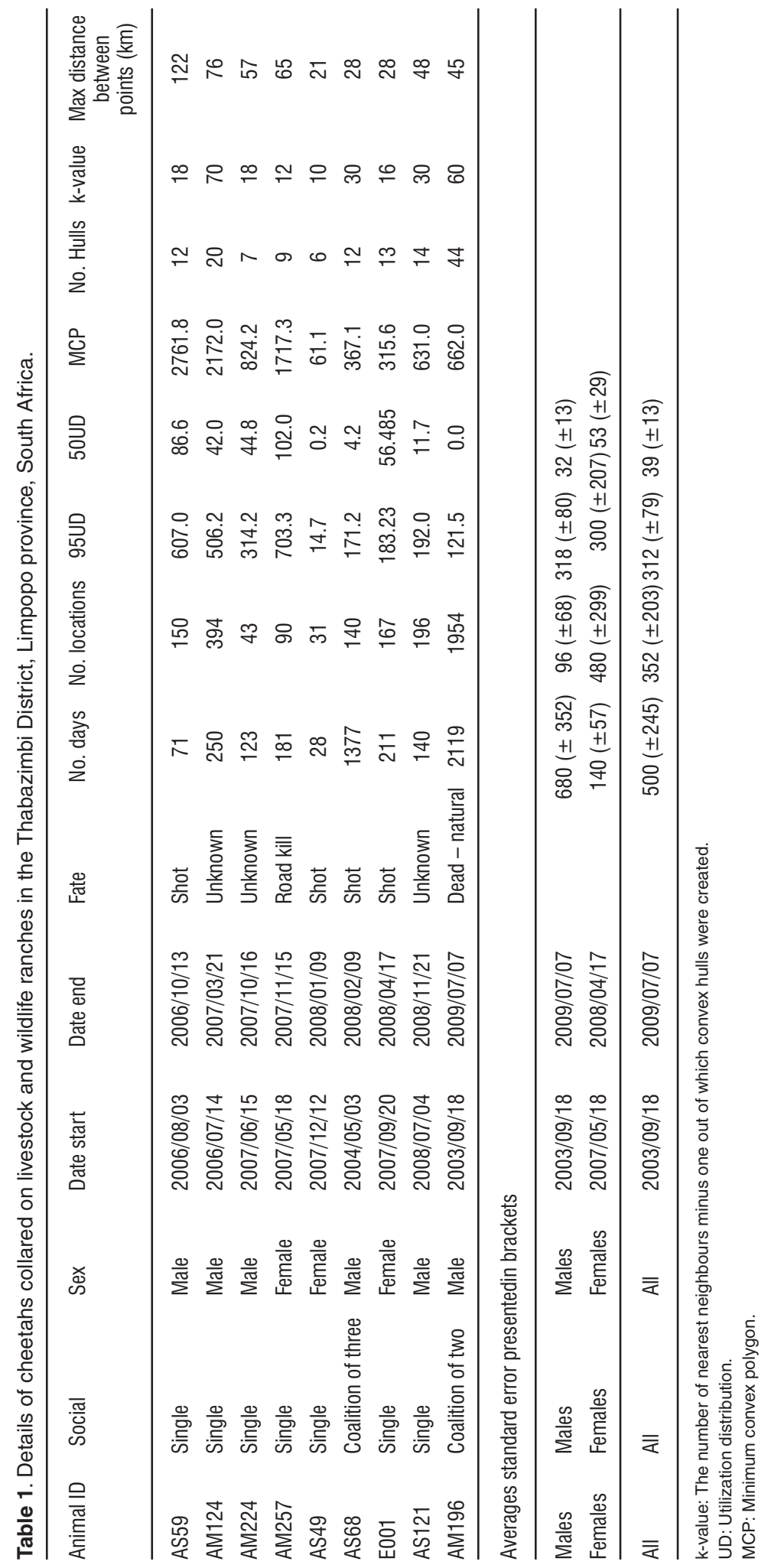


M124

Single male

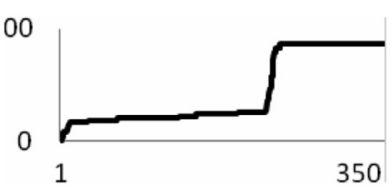

AM257

Female

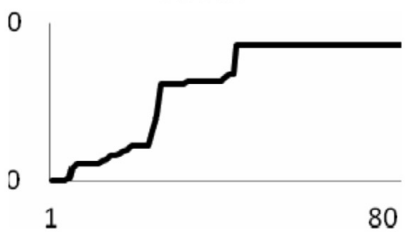

AS59

Single male

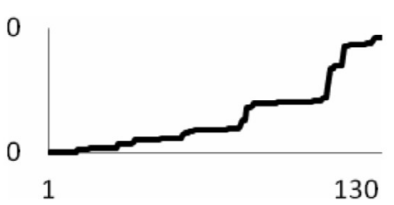

AM196

Two-male coalition

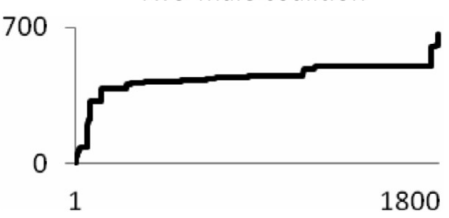

AS121

Single male

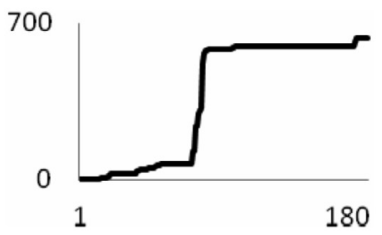

AS68

Three-male coalition

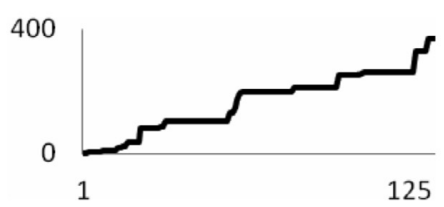

AM224

Single male

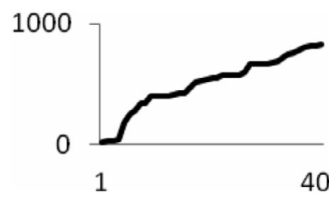

AS49

Female

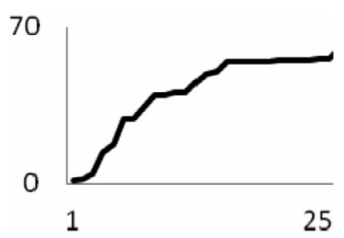

E001

Female

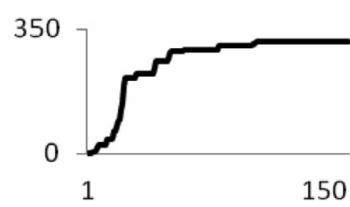

Fig. 2. Cheetah home range sizes measured over time. Y-axis denotes the size of the home range in $\mathrm{km}^{2}$ and the $x$-axis denotes the number of GPS locations used in the analysis.

Park (Fig. 4). Home ranges were generally larger than the average ranch size of $18 \mathrm{~km}^{2}$, with the average 95UD for all cheetahs covering approximately 18 properties. The average area of $12 \%$ of core utilization in relation to the 95UD in this study comprised similar percentages to those found in other studies in southern Africa: Namibia (average 13.9\%; Marker, Dickman, Mills, Jeo \& Macdonald, 2007), Botswana (males 11\%, females 10\%; Houser, Somers \& Boast, 2009) and Kruger (average 13\%; Broomhall, Mills \& du Toit, 2003) (Fig. 4), despite the large variation in home range sizes recorded between the studies. The reason for this is unknown and warrants further investigation.

The average size of the 50UDs for all cheetahs in this study was $42 \mathrm{~km}^{2}$ (Table 1) and is more than twice the size of the mean property size in the study area. The largest MCP was $2761.8 \mathrm{~km}^{2}$ for a male cheetah, this cheetah also had the second largest 95UD of all cheetahs. This is probably because he was a young male and dispersing from his maternal range. He moved over a large area and was eventually shot $c .78 \mathrm{~km}$ from the capture site. The coalition of two males had a very small 50UD, this was centred on a property that had a large area of relatively open vegetation where plains game congregated at an artificial feeding site. The landowner of the property in which the 50UD was focussed was fortunately cheetah friendly (K.M., pers. obs) and some anti-predation measures were taken to prevent excessive damage to the prey population. Predator-proof camps were constructed for a breeding project for expensive antelope breeds; these camps would have been constructed regardless of the cheetahs' presence to eliminate predation by other carnivores. The camps did present a problem in the form of small artificial watering point outside one of the camps. Antelope would congregate around the water point and the cheetahs chased the herds into the fence on a few occasions. This resulted in several antelope being injured and the fence getting damaged. This was finally resolved by closing the small water point.

The two-male coalition was the longest moni- 


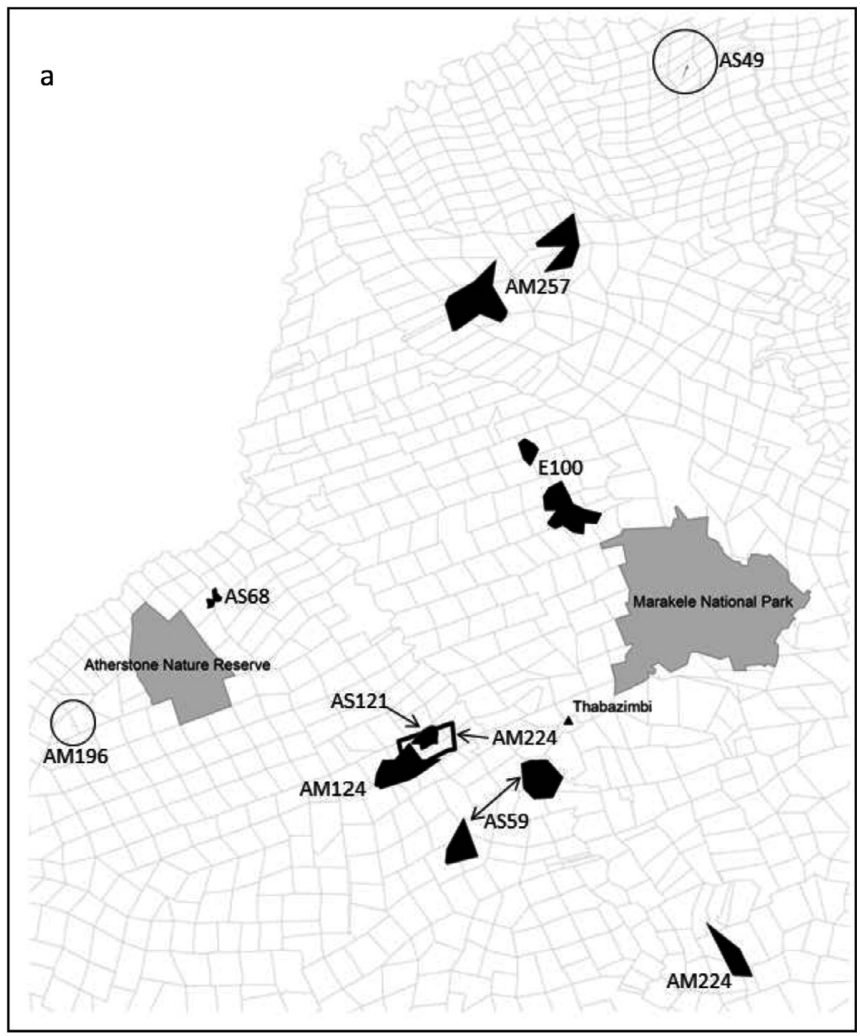

Fig. 3. a \& b, Fifty utilization distributions and 95 utilization distributions for cheetahs on livestock and wildlife ranches in the Thabazimbi district, Limpopo province. (Continued on p. 230.)

tored in the study and while their home range appeared to reach an asymptote, the last few GPS fixes showed an increase in the range size. This could be explained by the death of the coalition partner which has been shown to result in an increase in range by the remaining cheetah (Caro, 1994; Marker et al., 2007).

Cheetahs did not limit their movement to one individual property and moved over large areas as is generally typical for cheetahs in savanna habitats. This is despite the estimated high abundance of food and water, sedentary prey and the lack of intra-guild competition. The large home ranges of cheetahs in the Serengeti $\left(>800 \mathrm{~km}^{2}\right.$ females and $>777 \mathrm{~km}^{2}$ males; Caro, 1994) and the Kalahari (>320 km²; Mills, 1998) could be due to prey mobility; while the smaller ranges in Matusadona $\left(<100 \mathrm{~km}^{2}\right)$ could be due to prey congregating on the foreshore grassland (Purchase \& du Toit, 2000). However, patchy distribution of suitable hunting habitat could drive large range use, and especially in felids, suitable hunting habitat may influence range size more than prey availability (Kruuk, 1986).
Cheetah movements in woodland areas are influenced by the search for more open habitat suitable for hunting (Hunter, 1998). This could be the case in Thabazimbi as the bush is dense and open areas are scarce. The areas where the male coalitions centred their movement were previously ploughed, open grassland habitats in contrast to the hard boundaries of the surrounding densely wooded areas (pers. obs).

With the data available and no data on prey numbers and distribution, it is not known what drives the large range use of cheetahs in Thabazimbi. However, this study does provide useful information on the movement of cheetahs and shows that generally, cheetahs do not limit their movement to one property, thus causing excessive damage to the prey base on individual properties. However, there may be cases, like the two-male coalition, where cheetahs do have small areas of core utilization that could result in escalated conflict.

The patchy distribution of hunting habitat could also explain why cheetahs outside protected areas have larger ranges than cheetahs in Kruger. 


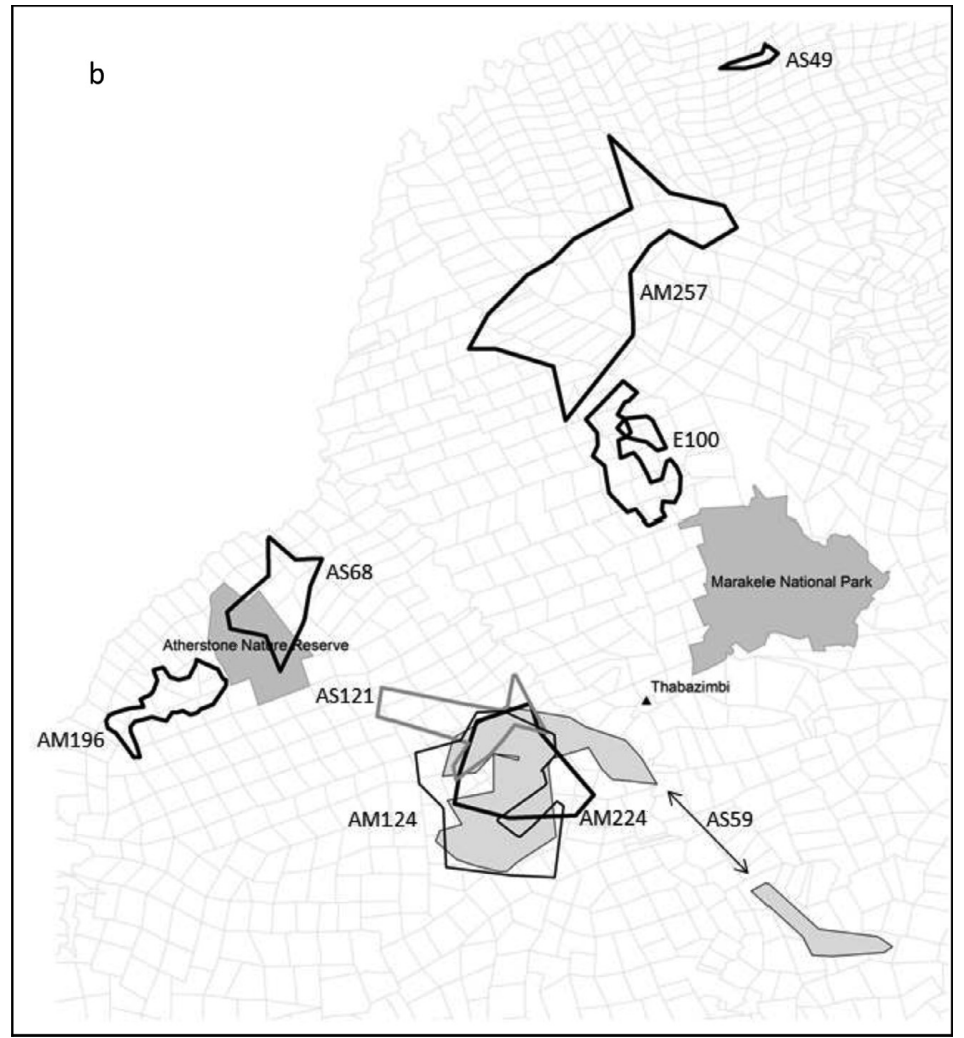

Fig. 3 (continued).

Ranching areas are prone to being over-utilized for long periods of time and, as a result, the vegetation becomes encroached. This makes more open areas sought after as hunting habitat for cheetahs. Additionally, cheetahs outside protected areas are affected by human disturbance that could require them to move larger distances to avoid conflict (Houser et al., 2009). It is likely that the large ranges of cheetahs outside protected areas are driven by the search for suitable habitat in an

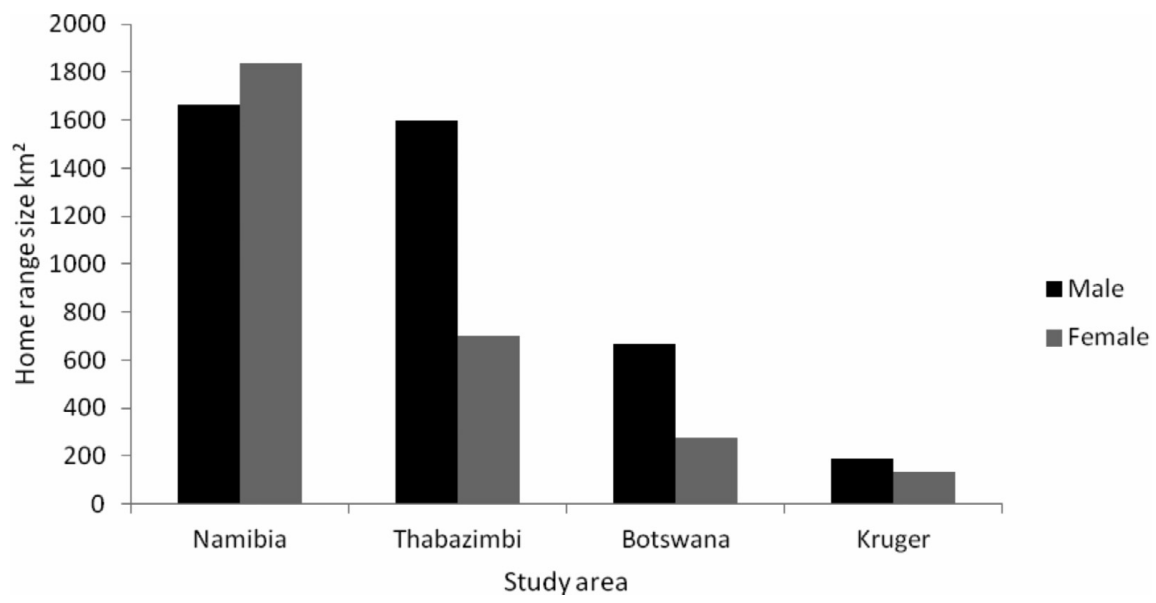

Fig. 4. Comparison of mean male and female cheetah home ranges sizes across study areas in southern Africa. Namibia (Marker et al., 2007), Botswana (Houser et al., 2009) and Kruger (Broomhall et al., 2003) using 95MCPs and Thabazimbi using MCPs. 
encroached environment and by human avoidance where cheetahs in Kruger have other range use drivers.

In this study, $44 \%$ of the collared cheetahs were shot by landowners while in Botswana 55\% of collared cheetahs were shot (Houser et al., 2009). These high levels of persecution highlight the need for effective conflict mitigation projects outside protected areas as high levels of humaninduced mortality could outweigh the advantages of a lack of intra-guild completion and a plentiful food and water resource. Most of southern Africa's cheetah population and distribution range occurs outside protected areas with approximately $22 \%$ (25 $8264 \mathrm{~km}^{2}$ of $1170479 \mathrm{~km}^{2}$ ) of cheetah range being protected and $23 \%$ (1460 of 6260 ) of cheetahs occurring inside protected areas (IUCN/ SSC, 2007), conflict can pose a significant challenge to the survival of the species.

\section{ACKNOWLEDGEMENTS}

Columbus Zoo, Cat Life Foundation, Duemke Family Trust, Scovill Zoo, Carston Springs Trust and the DST-NRF Centre for Excellence for Invasion Biology are thanked for funding. Peter Caldwell of Old Chapel Veterinary Clinic is thanked for immobilizing the cheetahs and being on constant standby. Willem Engelbrecht, the Jeurissen family of Silent Valley Safaris and Atherstone Nature Reserve provided logistical support. We thank all the other landowners who allowed access to their properties. The Limpopo Department of Economic Development, Environment and Tourism is thanked for permission to do the work in Limpopo province. Deon Cilliers and Luke Strugnellare thanked for help in the field. Scott Fortmann-Roe is thanked for advising on a technical problem. Gus Mills, John O'Brienand Matt Hayward are thanked for valuable input that greatly improved the manuscript.

\section{REFERENCES}

Balme, G.A., Slotow, R. \& Hunter, L.T.B. (2010). Edge effects and the impact of non-protected areas in carnivore conservation: leopards in the PhindaMkhuze Complex, South Africa. Animal Conservation, 13, 315-323.

Broomhall, L.S., Mills, M.G.L. \& du Toit, J.T. (2003). Home range and habitat use by cheetahs Acinonyx jubatus in the Kruger National Park. Journal of Zoology, 261, 119-128.

Cardillo, M., Mace, G.M., Jones, K.E., Bielby, J., Biminda-Emonds, O.R.P., Sechrest, W., Orme, C.D.L. \& Purvis, A. (2005). Multiple causes of high extinction in large mammal species. Science, 309, 1239-1241.
Caro, T.M. (1994).Cheetahs of the Serengeti Plains: group living in an asocial species. Chicago, U.S.A.: University of Chicago Press.

Friedmann, Y. \& Daly, B. (2004). Red data book of the mammals of South Africa: a conservation assessment. Johannesburg, South Africa: CBSG Southern Africa, Endangered Wildlife Trust.

Getz, W.M. \& Wilmers, C.C. (2004). A local nearestneighbour convex-hull construction of home ranges and utilization distributions. Ecography, 27, 1-17.

Getz, W.M., Fortmann-Roe, S.B., Lyons, A., Ryan, S. \& Cross, P. (2007). LoCoH methods for the construction of home ranges and utilization distributions. PLOS ONE, 2(2), e207. doi:10.1371/journal.pone. 0000207

Harris, S., Cresswell, W.J., Forde, P.G., Trewhella, W.J., Woollard, T. \& Wray, S. (1990). Home-range analysis using radio-tracking data - a review of problems and techniques particularly as applied to the study of mammals. Mammal Review, 20, 97-123.

Houser, A-M., Somers, M.J. \& Boast, L.K. (2009). Home range use of free-ranging cheetah on farm and conservation land in Botswana. South African Journal of Wildlife Research, 39(1), 11-22.

Hunter, L.T.B. (1998). The behavioural ecology of reintroduced lions and cheetahs in the Phinda Resource Reserve, KwaZulu-Natal, South Africa. (Unpublished Ph.D. thesis). Pretoria, South Africa: University of Pretoria.

IUCN/SSC. (2006). Regional lion conservation strategy for the lion Panthera leo in eastern and southern Africa. Gaborone, Botswana: IUCN.

IUCN/SSC (2007). Regional Conservation Strategy for the Cheetah and African Wild Dog in Southern Africa. Gland, Switzerland: IUCN.

Jenrich, R.I. \& Turner, F.B. (1969). Measurement of noncircular home range. Journal of Theoretical Biology, 22, 227-237.

Kruuk, H. (1986). Interactions between Felidae and their prey species: a review. In S.D. Miller \& D.D. Everett (Eds), Cats of the world: biology, conservation and management (pp. 253-273). Washington, DC, U.S.A.: National Wildlife Federation.

Laurenson, M.K. (1995). Implications of high offspring mortality for cheetah population dynamics. In A.R.E. Sinclair \& P. Arcese (Eds), Serengeti II: Dynamics, management, and conservation of an ecosystem ( $\mathrm{pp}$. 385-399). Chicago, U.S.A.: University of Chicago Press.

Laver, P.N. (2005). ABODE: Kernel home range estimation for ArcGIS, using VBA and ArcObjects. Blacksburg, U.S.A.: Virginia Tech University.

Lindsey, P.A. \& Davies-Mostert, H.T. (Eds) (2009). South African action plan for the conservation of cheetahs and African wild dogs. Johannesburg, South Africa: Endangered Wildlife Trust, IUCN.

Low, A.B. \& Rebelo, A.G. (1996). Vegetation of South Africa, Lesotho and Swaziland. Pretoria, South Africa: Department of Environmental Affairs and Tourism.

Margules, C.R. \& Pressey, R.L. (2000).Systematic conservation planning. Nature, 405, 243-253.

Marker, L.L., Dickman, A.J., Mills, M.G.L., Jeo, R.M. \& Macdonald, D.W. (2007). Spatial ecology of cheetahs 
on north-central Namibian farmlands. Journal of Zoology, 274, 226-238.

Marnewick, K. \& Cilliers, D. (2006). Range use of two coalitions of male cheetahs Acinonyx jubatus in the Thabazimbi district of the Limpopo province. South African Journal of Wildlife Research, 36(2), 147-151.

Marnewick, K., Bothma, J. du P. \& Verdoorn, G.H. (2006). Using camera-trapping to investigate the use of a tree as a scent-marking post by cheetahs in the Thabazimbi district. South African Journal of Wildlife Research, 36(2), 139-145.

Marnewick, K., Beckhelling, A., Cilliers, D., Mills, G., Herring, K., Caldwell, P., Hall, R. \& Meintjes, S. (2007). The status and conservation needs of the cheetah in southern Africa. Cat News, Special Issue 3, 22-31.

Miller, S.M., Bissett, C., Burger, A., Courtenay, B., Dickerson, T., Druce, D.J., Ferreira, S., Funston, P.J., Hofmeyr, D., Kilian, P.J., Mathews, W., Naylor, S., Parker, D.M., Slotow, R., Toft, M. \& Zimmerman, D. (2013). Management of reintroduced lions in small, fenced reserves in South Africa: an assessment and guidelines. South African Journal of Wildlife Research, 43(2), 138-154.

Mills, M.G.L. (1998). Cheetah ecology and behaviour in East and South Africa In B.L. Penzhorn (Ed.), Cheetahs as game ranch animals: Proceedings of a symposium on cheetahs as game ranch animals (pp. 8-22). Onderstepoort, South Africa: South African Veterinary Association.

Purchase, G. \& du Toit, J.T. (2000). The use of space and prey by cheetahs in Matusadona National Park,
Zimbabwe. South African Journal of Wildlife Research, 30, 139-144.

Purvis, A., Gittleman, J.L., Cowlishaw, G. \& Mace, G.M. (2000). Predicting extinction risk in declining species. Proceedings of the Royal Society of London B, 267, 1947-1952.

Ranta, P., Blom, T., Niemela, J., Joensuu, E. \& Siitonen, M. (2009). The fragmented Atlantic rain forest of Brazil: size, shape and distribution of forest fragments. Biodiversity \& Conservation, 7,385-403.

Swanepoel, L.H., Lindsey, P., Somers, M.J., van Hoven, W. \& Dalerum, F. (2013). Extent and fragmentation of suitable leopard habitat in South Africa. Animal Conservation, 16, 41-50.

Swanepoel, L.H., Lindsey, P., Somers, M.J., van Hoven, W. \& Dalerum, F. (2014). The relative importance of trophy harvest and retaliatory killing of large carnivores: South African leopards as a case study. South African Journal of Wildlife Research, 44(2), 115-134.

Thorn, M., Green, M., Marnewick, K. \& Scott, D. (2013). Characteristics and determinants of human-carnivore conflict in South African farmland. Biodiversity \& Conservation, 22(8), 1715-1730.

Wilson, K. (2006). Status and distribution of cheetah outside formal conservation areas in the Thabazimbi district, Limpopo province. (Unpublished M.Sc. thesis). University of Pretoria, Pretoria, South Africa. Woodroffe, R. \& Ginsberg, J.R. (1998). Edge effects and the extinction of populations inside protected areas. Science, 280, 2126-2128.

Worton, B.J. (1989). Kernel methods for estimating the utilization distribution in home range studies. Ecology, 70, 164-168. 